\title{
Effects of Conditional Central Expression of HIV-I Tat Protein to Potentiate Cocaine-Mediated Psychostimulation and Reward Among Male Mice
}

\author{
Jason J Paris', Amanda N Carey ${ }^{2,3}$, Christopher F Shay', Stacey M Gomes ${ }^{1,2}$, Johnny J He ${ }^{4}$ and \\ Jay P McLaughlin*, ${ }^{*, 2}$
}

'Department of Pharmacology and Neuroscience, Torrey Pines Institute for Molecular Studies, Port Saint Lucie, FL, USA; ${ }^{2}$ Department of Psychology, Northeastern University, Boston, MA, USA; ${ }^{3}$ Department of Psychology, Simmons College, Boston, MA, USA; ${ }^{4}$ Department of Cell Biology and Anatomy, University of North Texas Health Science Center, Fort Worth, TX, USA

\begin{abstract}
As a major neuropathogenic factor associated with human immunodeficiency virus (HIV) infection, HIV-I Tat protein is known to synergize with psychostimulant drugs of abuse to cause neurotoxicity and exacerbate the progression of central nervous system pathology. However, the functional consequences of the interaction between HIV-I Tat and abused drugs on behavior are little known. We tested the hypothesis that HIV-I Tat expression in brain would modulate the psychostimulant effects of cocaine. Using the GT-tg bigenic mouse model, where brain-selective Tat expression is induced by activation of a doxycycline (Dox) promotor, we tested the effects of Tat on cocaine ( $10 \mathrm{mg} / \mathrm{kg}$, s.c.) induced locomotion and conditioned place preference (CPP). Compared with uninduced littermates or C57BL/6J controls, cocaine-induced hyperlocomotion was sustained for a significantly longer duration among Tat-induced mice. Moreover, although all groups displayed similar saline-CPP, Tat-induced GT-tg mice demonstrated a three-fold increase in cocaine-CPP over the response of either uninduced littermates or Dox-treated C57BL/6) control mice. Induction of Tat also increased the magnitude of a previously established cocaine-CPP after an additional cycle of cocaine place-conditioning. Despite Tat-induced potentiation, extinction of place preference occurred within 21 days, commensurate with cocaine-extinction among saline-treated littermates and C57BL/6J controls. Re-exposure to cocaine produced reinstatement of an equivalent place preference in Tat-induced GT-tg or C57BL6) mice; however, induction of Tat protein after the extinction of CPP also produced reinstatement without additional exposure to cocaine. Together, these data suggest that central HIV-I Tat expression can potentiate the psychostimulant behavioral effects of cocaine in mice.

Neuropsychopharmacology (2014) 39, 380-388; doi:I0. I038/npp.20 I3.20 I; published online II September 2013
\end{abstract}

Keywords: cocaine; drug abuse; HIV-I; neuroAIDS; Tat; transgenic

\section{INTRODUCTION}

Psychostimulants are highly abused in both general and human immunodeficiency virus (HIV)-infected populations (Gorman, 1998), and psychostimulant abusers comprise one of the fastest growing populations of HIV-infected patients (Nath et al, 2002; UNAIDS/WHO, 2005). HIV-infected, drug-abusing individuals may experience more severe or faster-progressing HIV-1 related neurological impairment (UNAIDS/WHO, 2005). Dopaminergic systems otherwise known to mediate drug reward (Di Chiara et al, 2004; Kalivas and Volkow, 2005; Purohit et al, 2011) may be modified by chronic cocaine use (such as the up- or downregulation of cocaine recognition sites on dopamine (DA) transporters; Malison et al, 1998; Staley et al, 1994;

*Correspondence: Dr JP McLaughlin, Department of Biology, Torrey Pines Institute for Molecular Studies, I 350 SW Village Parkway, Port Saint Lucie, FL 34987, USA, Tel: +772 345 47I 5, Fax: +772 3453649 , E-mail: jmclaughlin@tpims.org

Received 12 June 20 I3; revised 12 July 20 I3; accepted 12 August 20 I3; accepted article preview online 15 August 2013
Wilson et al, 1996), and are also implicated in the pathogenesis of HIV-1-associated neurological complications (Berger and Arendt, 2000; Cass et al, 2003). Consistent with this, autopsy of HIV-1 infected brains demonstrates infiltration of HIV-infected cells in DA-rich regions (Navia et al, 1986), and such patients often present comorbid clinical signs common to dopaminergic disorders (Nath, 1999). However, the HIV-1-mediated mechanisms that may interact with drugs of abuse, influencing behavioral reward and/or central pathology, remain poorly understood.

Given that HIV-1 does not infect neurons, indirect mechanisms may underlie neurological sequelae. Tat is a polypeptide that transactivates HIV-1 gene expression (Wei et al, 1998) and is implicated in HIV-related neurological complications (Frankel and Young, 1998; Yao and Buch, 2012). In fact, specific mutations within the first exon of the Tat gene correlate with HIV clade-specific differences in the prevalence of HIV dementia (Sacktor et al, 2009) and human neuron toxicity (Rao et al, 2008; Mishra et al, 2008). Furthermore, Tat exposure is known to contribute to dysfunction of the 
dopaminergic system (Maragos et al, 2002; Yao and Buch, 2012), influencing DA recycling (Ferris et al, 2009), uptake kinetics (Zhu et al, 2009), and causing rapid DA transporter (DAT) dysfunction (Wallace et al, 2006; Zhu et al, 2011). Given that drug reward is thought to involve the mesolimbic DA pathway, the ability of Tat to promote dopaminergic dysfunction implies a biological mechanism by which Tat may modulate drug reinforcement, but behavioral determinations are lacking.

We hypothesized that expression of HIV-1 Tat protein in a rodent model would potentiate the behavioral psychostimulant response to cocaine. We tested the effects of Tat expression on cocaine-induced locomotion and reward using the GT-tg bigenic mouse (Kim et al, 2003). These transgenic mice have a Tat 'knock in' gene encoding 86 amino acids from the first and second exons of HIV-1 HXB2. Tat expression is controlled using a tet-on inducible system, which becomes transcriptionally active when doxycycline (Dox) is introduced. The gene is driven by the astrocyte-specific glial fibrillary acidic protein (GFAP) promotor, resulting in brainspecific Tat protein expression when induced (Kim et al, 2003). Tat-induced mice recapitulate many clinical findings of HIV-1 infection, including central macrophage/monocyte infiltration, T-lymphocyte infiltration, and neuronal cell death (Kim et al, 2003). Using Western blot analysis, we previously established that the magnitude of Tat expression correlates with the treatment dose of Dox and duration of Dox administration (Carey et al, 2012). Exposure to Tat protein results in behavioral deficits of learning and memory and reductions of gray-matter density in limbic regions of GT-tg mouse brains as measured with ex vivo magnetic resonance imaging (Carey et al, 2013). Accordingly, we utilized this mouse model to determine if HIV-Tat protein is sufficient to alter the behavioral effects and rewarding properties of a commonly abused psychostimulant, cocaine.

\section{MATERIALS AND METHODS}

\section{Animals and Housing}

Adult male GT-tg bigenic and C57BL/6J wild-type (Jackson Labs, Bar Harbor, ME) mice (7-10 weeks of age) were maintained in the Northeastern University and Torrey Pines Institute animal facilities. All experiments were preapproved by respective Institutional Animal Care and Use Committees in accordance with the 1996 National Institutes of Health Guide for the Care and Use of Laboratory Animals. The creation of the GT-tg bigenic mice and the genotype confirmation of the inducible and brain-targeted HIV-Tat protein was described previously (Carey et al, 2013; Kim et al, 2003).

\section{Chemicals}

Chemicals were obtained from Sigma-Aldrich (St Louis, $\mathrm{MO})$. Cocaine $(10 \mathrm{mg} / \mathrm{kg}$ ) and Dox hyclate (see below) were dissolved in $0.9 \%$ saline before injection.

\section{Induction of Brain-Targeted Tat with Dox Treatment}

To express Tat $_{1-86}$, GT-tg bigenic mice were administered Dox via i.p. injection with a single daily dose $(25,50$, or
$100 \mathrm{mg} / \mathrm{kg}$ ), dissolved in $0.9 \%$ saline in a volume of $0.3 \mathrm{ml} /$ $30 \mathrm{~g}$ body weight for $1,3,5$, or 7 days as indicated and characterized previously (Carey et al, 2013). However, the majority of induction experiments utilized a dose of $100 \mathrm{mg} /$ $\mathrm{kg}$, i.p. once daily for 7 days, given that we have previously observed this dose to have the greatest efficacy inducing central Tat protein expression (Carey et al, 2013). GT-tg mice administered saline ('uninduced') and C57BL/6J mice administered saline or Dox provide respective isogenic and congenic, negative controls.

\section{Locomotor Activity}

Distance traveled $(\mathrm{cm})$ was recorded using the Noldus EthoVision Pro tracking software as described previously by Carey et al (2009). After $60 \mathrm{~min}$ of habituation to the testing arena, mice were administered saline $(0.9 \%$, s.c.) or cocaine $(10 \mathrm{mg} / \mathrm{kg}, \mathrm{s.c}$.$) and activity was measured for 30 \mathrm{~min}$.

\section{Conditioned Place Preference (CPP)}

Mice were conditioned via a biased cocaine-CPP paradigm with the apparatus and automated measurement system (San Diego Instruments, San Diego, CA) described by Carey et al (2007). Animals were treated with vehicle (0.9\% saline) or Dox $(25-100 \mathrm{mg} / \mathrm{kg})$ for $1,3,5$, or 7 days as described above. Note that this treatment was administered before the start of conditioning, although two sets of mice received Dox (100 mg/kg, 7 days) following completion of conditioning to test for the ability of Tat protein to alter established place preference responses (see Results). An initial preconditioning preference was determined by measuring the amount of time the individual mice spent in each chamber during a 30-min testing period. After administration of cocaine, mice were immediately confined for $30 \mathrm{~min}$ in the initially non-preferred chamber. Conditioning with vehicle ( $0.9 \%$ saline, s.c.) followed $4 \mathrm{~h}$ later in a similar manner, but paired to the initially preferred chamber. This cocainesaline conditioning 'cycle' was repeated for two cycles, one cycle per day. Mice were tested for preference $24 \mathrm{~h}$ after the completion of conditioning by allowing the mice free access to the apparatus and measuring the time they spent in each chamber over a 30-min testing period. Notably, detection of positive CPP in similarly 'biased' designs can be influenced by anti-aversive or anti-anxiety-like effects that are unrelated to the rewarding aspects of drug manipulation (Carr et al, 1989). However, these concerns are minimized in the present experimental design given that neither cocaine nor Tat would be expected to reduce anxiety-like behavior. Indeed, cocaine may potentiate fear and/or anxiety behaviors among mice (Blanchard and Blanchard, 1999), and any effects of Tat induction on anxiety-like status are expected to be similar given recent demonstrations of HIV-Tat on negative mood-like states of mice (Lawson et al, 2011).

\section{Extinction and Reinstatement Testing}

Mice were place-conditioned for four cycles and the place preference response to cocaine made extinct similar to previously described methods (Carey et al, 2007). The conditioning cycle was repeated once per day for 4 days. 
The four-cycle paradigm has been demonstrated to be optimal for producing a long-lasting CPP using this dose of cocaine (Brabant et al, 2005). Place-conditioned mice were subsequently tested twice weekly for place preference until they demonstrated extinction, defined as the return of the preference response to values statistically similar to initial responses (Brabant et al, 2005; Carey et al, 2007). Upon demonstration of extinction, reinstatement of drug preference was examined after exposure to an additional cocaine-saline cycle of place-conditioning (Carey et al, 2007). Note that exposing C57BL/6 J mice to a single cycle of place-conditioning has been found to be insufficient to produce cocaine-CPP (McLaughlin et al, 2003; Brabant et al, 2005). Reinstatement preference was examined $24 \mathrm{~h}$ after the single cycle of conditioning.

\section{Statistical Analysis}

Locomotor activity was analyzed via three-way repeated measures ANOVA (with 'strain,' 'Dox condition,' and 'cocaine condition' as between-subjects factors and 'time from cocaine administration' as the within-subjects factor). CPPs were assessed via one-way ANOVA (when factors were 'Dox dose' or 'days of Dox exposure'), two-way ANOVA (when factors were 'strain' and 'Dox condition'), and repeated measures ANOVA (when assessing extinction and reinstatement). Main effects were followed by Tukey's HSD post hoc tests to delineate significant group differences. Interactions were assessed via simple main effects followed by main effect contrasts to assess group differences. All effects were considered significant when $p<0.05$ in a Bonferroni-corrected manner to control for family-wise error. Data are presented as mean \pm SEM.

\section{RESULTS}

\section{Exposure to HIV-1 Tat Potentiated Cocaine-Induced Locomotor Activity}

We first assessed the behavioral effect of brain-specific HIV-1 Tat protein on psychostimulants by examining the locomotor activity induced by cocaine $(10 \mathrm{mg} / \mathrm{kg}$, s.c.). GT-tg bigenic mice or C57BL/6J mice were pretreated daily with vehicle (0.9\% saline, i.p.) or Dox ( $100 \mathrm{mg} / \mathrm{kg}$, i.p.) for 7 days before locomotor testing. All independent variables interacted $\left(\mathrm{F}_{(2,152)}=3.12, p<0.05\right)$ such that mouse strain, cocaine administration, Dox exposure, and time across the 30 min testing session all contributed to the distance $(\mathrm{cm})$ mice traveled in the open field (Figure 1). Among C57BL/6J control mice (see circles in Figure 1), simple main effects indicated that mice traveled a significantly greater distance $\left(F_{(2,132)}=5.53, p=0.005\right)$ in the first $10(p=0.001)$ or 20 $(p=0.04) \mathrm{min}$, compared with locomotion by $30 \mathrm{~min}$ in the task. Compared with saline, cocaine administration significantly increased the distance traveled across the task $\left(\mathrm{F}_{(1,132)}=18.05, p<0.0001\right)$. Similarly, the distance traveled among GT-tg bigenic mice (see squares in Figure 1) was significantly greater $\left(\mathrm{F}_{(2,96)}=11.60, p<0.0001\right)$ in the first $10(p<0.0001)$ or $20(p=0.002)$ min than that observed by $30 \mathrm{~min}$ in the locomotion task. Unlike C57BL/6J controls, Dox administration to GT-tg mice significantly enhanced cocaine's effects to increase the distance traveled

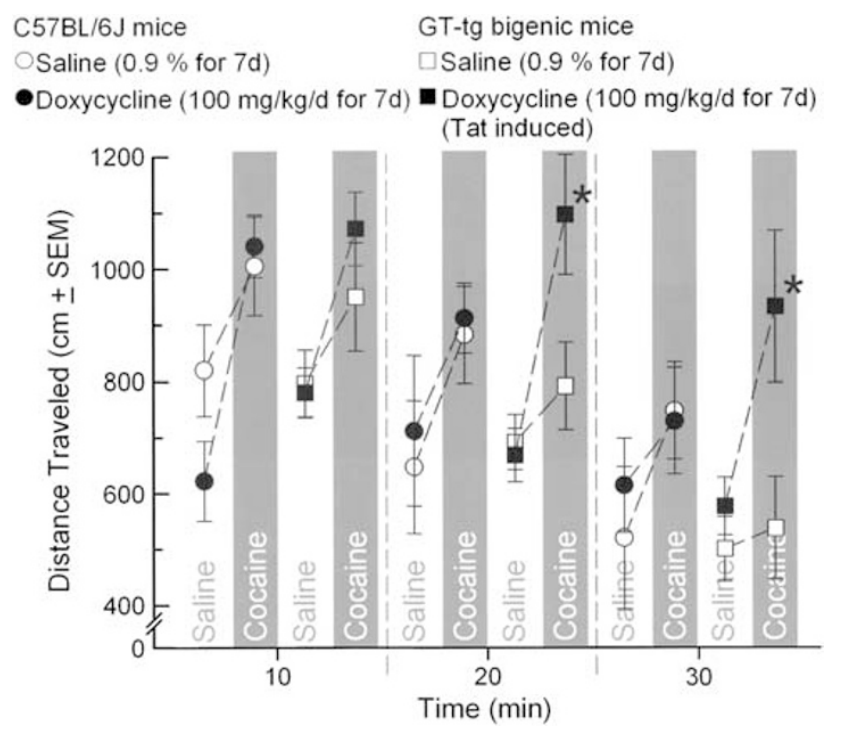

Figure I Induction of human immunodeficiency virus I (HIV-I) Tat potentiated the duration of cocaine-induced locomotor activity. C57BL/6) (circles) or GT-tg bigenic (squares) mice were pretreated for 7 days with vehicle (saline $0.9 \%$, i.p.; depicted as open icons) or Dox (100 mg/ $/ \mathrm{kg}$, i.p.; depicted as filled icons) and administered saline (0.9\%, s.c.) or cocaine ( $10 \mathrm{mg} / \mathrm{kg}$, s.c.) before locomotor assessment in an open field for $30 \mathrm{~min}$. Cocaine significantly increased the distance $(\mathrm{cm})$ traveled in the open field amongst all groups compared with saline, but this potentiation was greater among Tat-induced GT-tg mice than other groups following the initial $10 \mathrm{~min}$ in the task. *Indicates significant difference from uninduced GT-tg bigenic mice, $p<0.05$, repeated measures analysis of variance (ANOVA).

$\left(\mathrm{F}_{(1,96)}=8.32, p=0.005\right)$ by $20(p=0.04)$ or $30(p=0.01)$ min compared with the effect observed after the first 10 min in the task. Thus, the locomotor effects of cocaine observed in the first $10 \mathrm{~min}$ of the task were potentiated at 20 and 30 min among GT-tg mice expressing the Tat transgene.

\section{HIV-1 Tat Potentiated Cocaine-Conditioned Place Preference}

To initially test the hypothesis that HIV-1 Tat protein expression would potentiate the rewarding effect of psychostimulants, C57BL/6J and GT-tg bigenic mice were treated with vehicle $(0.9 \%$ saline, i.p.) or Dox $(100 \mathrm{mg} / \mathrm{kg}$, i.p.) once daily for 7 days. Following treatment, all mice were place-conditioned with cocaine $(10 \mathrm{mg} / \mathrm{kg}$, s.c.) for 2 days as described in the Methods. Mice were tested for final preference $24 \mathrm{~h}$ after the completion of conditioning.

Before conditioning, there were no significant differences between the initial place preference responses of Tat-induced $(-224 \pm 36 \mathrm{~s})$ or uninduced $(-193 \pm 29 \mathrm{~s})$ GT-tg bigenic mice, and those of vehicle-pretreated $(-195 \pm 26 \mathrm{~s})$ or Doxpretreated C57BL/6J mice $(-232 \pm 54 \mathrm{~s}) \quad\left(\mathrm{F}_{(8,127)}=1.00\right.$, $p=0.41$, NS). Following conditioning, all groups demonstrated cocaine-CPP, as indicated by a significant increase in the time mice spent in the cocaine-paired chamber compared with matching pre-conditioning baseline responses $\left(\mathrm{F}_{(8,127)}=5.66, p<0.05\right) \quad$ (Figure $\left.2 \mathrm{a}\right)$. However, Dox-treated GT-tg mice demonstrated a potentiation of cocaine-CPP that was significantly greater than postconditioning responses of either the vehicle- $(p<0.001)$ or Dox-pretreated $(p<0.01)$ C57BL/6J mice or uninduced GT-tg bigenic mice ( $p<0.001$; Figure 2a). Significant differences in 
post-CPP responses were not observed among negative control groups (vehicle- or Dox-pretreated C57BL/6J mice, or uninduced GT-tg bigenic mice).

As a control to verify the need for cocaine in place preference conditioning, an experiment was conducted wherein cocaine was replaced with saline in the conditioning trials. Data indicated no significant increase in the time spent in the non-preferred chamber compared with the matching pre-conditioning preference (data as pre- $v s$ post-CPP: C57BL/6J, $-183 \pm 42$ vs $-136 \pm 62 \mathrm{~s}, p=0.35$; uninduced GT-tg, $\quad-182 \pm 56$ vs $-41 \pm 70 \mathrm{~s}, \quad p=0.23$; Tat-induced GT-tg, $-228 \pm 76$ vs $-93 \pm 151, p=0.3$, NS).

\section{HIV-1 Tat Potentiated Cocaine-CPP in a Dose- and Duration-Dependent Manner}

To test the hypothesis that HIV-1 Tat expression influences psychostimulant reward in an exposure-dependent manner,
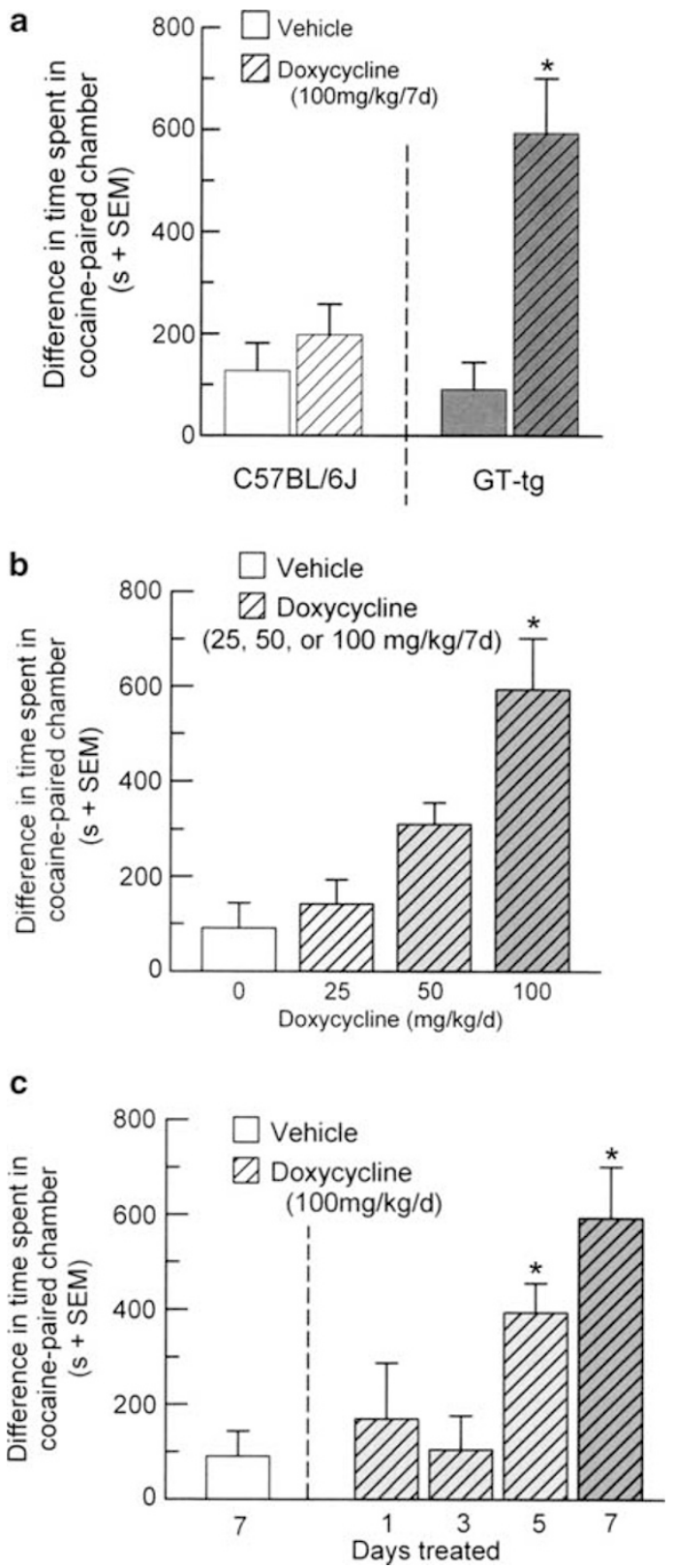

additional GT-tg bigenic mice were administered saline or one of three different doses of Dox $(25,50$ or $100 \mathrm{mg} / \mathrm{kg}$, i.p.) for 7 days, or a $100 \mathrm{mg} / \mathrm{kg}$ dose for one of four different durations (1, 3, 5 or 7 days). The Tat-induced potentiation of cocaine-CPP proved dependent on the dose $\left(\mathrm{F}_{(3,182)}=8.18, \quad p<0.05\right) \quad$ (Figure 2b) and duration $\left(\mathrm{F}_{(4,182)}=6.53, p<0.05\right)$ (Figure $2 \mathrm{c}$ ) of Dox administration. The cocaine-CPP responses of GT-tg mice administered 25 and $50 \mathrm{mg} / \mathrm{kg}$ Dox for 7 days were not significantly greater than those of uninduced GT-tg bigenic mice $(p=0.99$ and $p=0.38$, respectively; Figure $2 \mathrm{~b}$ ). However, the final preference of mice induced for 7 days with $50 \mathrm{mg} / \mathrm{kg}$ was also not significantly different than the final preference of the mice administered $100 \mathrm{mg} / \mathrm{kg}$ for 7 days $(p=0.20$; Figure 2b), suggesting a Dox-induction dose-dependent increase in cocaine-CPP. Likewise, when compared with uninduced mice, GT-tg mice administered $100 \mathrm{mg} / \mathrm{kg}$ Dox for 5 , but not 1 or 3 days, demonstrated a potentiation of cocaine-CPP $(p<0.05$; Figure $2 c)$. Post-conditioning preference for cocaine did not differ for mice administered $100 \mathrm{mg} / \mathrm{kg}$ Dox for 5 or 7 days $(p=0.63)$. Together, these results suggest that the magnitude (dose and duration) of Dox administration determined the degree of Tat-induced potentiation of cocaine-CPP.

\section{Effects of HIV-1 Tat Exposure on Established Cocaine-CPP}

We next determined whether exposure to Tat protein could potentiate the rewarding effects of cocaine among subjects already place-conditioned with cocaine and demonstrating a place preference. Two groups of untreated GT-tg bigenic mice place-conditioned with cocaine daily for 2 days (see squares in Figure $3 a$ schematic) demonstrated equivalent

Figure 2 Human immunodeficiency virus I (HIV-I) Tat induction potentiated cocaine-conditioned place preference (CPP). (a). Postconditioning preference was potentiated in Tat-induced mice. C57BL/6) mice (white bars left of dashed line) pretreated with Dox ( $100 \mathrm{mg} / \mathrm{kg}$, striped white bar) demonstrated a cocaine-CPP that was similar to vehiclepretreated C57BL 6 ) mice ( $0.9 \%$ saline, solid white bar), demonstrating that there was no effect of Dox pretreatment itself on CPP. Post-conditioning responses of the C57BL/6) and uninduced GT-tg mice (solid gray bar right of dashed line) did not differ significantly from each other. In contrast, Tatinduced GT-tg mice (striped gray bar) showed a significantly increased cocaine-CPP compared with C57BL/6) and uninduced mice. (*Indicates significant difference from all other post-CPP responses, $p<0.05$, two-way analysis of variance (ANOVA). (b) Tat-induced potentiation of cocaine-CPP was Dox dose-dependent. GT-tg bigenic mice induced with $25 \mathrm{mg} / \mathrm{kg}$ Dox for 7 days (striped white bar) did not demonstrate a significantly potentiated cocaine-CPP compared with vehicle-pretreated (ie, uninduced, solid white bar) GT-tg bigenic mice. GT-tg mice administered $50 \mathrm{mg} / \mathrm{kg}$ Dox for 7 days (striped gray bar) showed an elevated cocaine-CPP, which did not differ from uninduced mice, but also did not differ from mice induced with the maximum Dox dose ( $100 \mathrm{mg} / \mathrm{kg}, 7$ days, striped dark gray bar). (*Indicates significant difference from uninduced GT-tg bigenic mice, $p<0.05$, one-way ANOVA.). (c) Potentiation of cocaine-CPP was dependent on the length of induction of Tat. GT-tg bigenic mice induced with $100 \mathrm{mg} / \mathrm{kg}$ Dox for I or 3 days (first and second striped light gray bars, respectively) did not demonstrate a significant difference in cocaine-CPP as compared with uninduced GT-tg bigenic mice (solid white bar). However, mice administered $100 \mathrm{mg} / \mathrm{kg}$ Dox for 5 and 7 days (third and fourth striped gray bars, respectively) showed a significant potentiation of cocaine-CPP compared with uninduced mice. *Indicates significant difference from uninduced GT-tg bigenic mice, $p<0.05$, one-way analysis of variance (ANOVA.) 

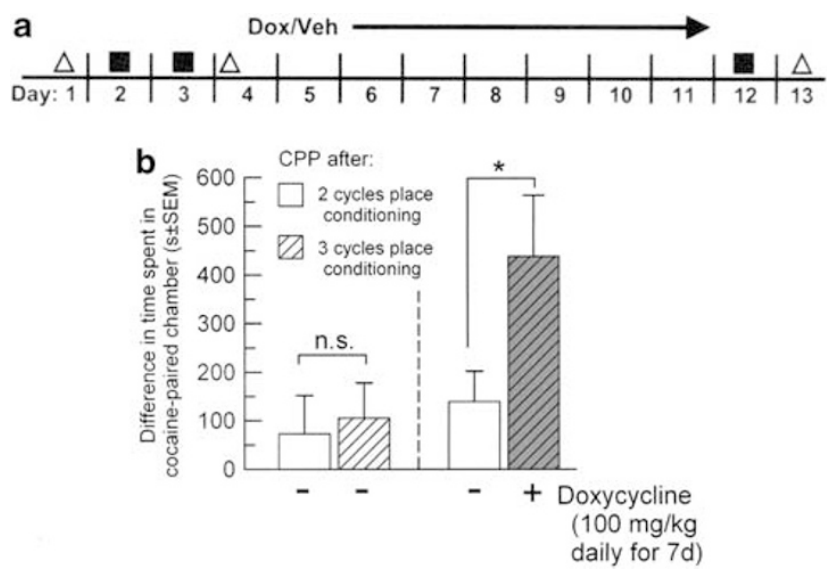

Figure 3 Induction of Tat potentiated the reward associated with previously established, cocaine-conditioned place preference (CPP). (a) Schematic of experimental design. Uninduced GT-tg bigenic mice were tested for place preference (triangles) the days before and after place-conditioning with cocaine and saline for 2 days (squares). Mice were then either administered doxycycline (Dox) to induce Tat expression or control vehicle (Veh) daily for 7 days. Treated mice were given an additional cycle of conditioning (day 12) and re-tested for place preference (day 13). (b) Dox treatment potentiates a previously established CPP after an additional cycle of place-conditioning. Both groups of uninduced mice demonstrated equivalent post-conditioning cocaine preference (open bars). Vehicle-treated mice given an additional cycle of conditioning demonstrated no change in cocaine place-preference (striped white bar to the left of dashed line). However, Tat-induced mice displayed a postinduction cocaine-CPP (striped gray bar) that was significantly potentiated from both the previous matching group preference (striped white bar to the left of dashed line) and the preference of the vehicle-treated uninduced mice (solid white bar to right of dashed line). *Indicates significant difference from uninduced GT-tg bigenic mice, $p<0.05$; NS, no significant difference between groups, one-way analysis of variance (ANOVA)

post-conditioning preference for the cocaine-paired chamber $(73 \pm 80 \mathrm{~s}$ and $140 \pm 63 \mathrm{~s}) \quad\left(\mathrm{F}_{(1,40)}=0.44, \quad p=0.51\right)$ (Figure $3 \mathrm{~b}$, open bars). Upon demonstration of place preference, mice were administered Dox $(100 \mathrm{mg} / \mathrm{kg}$, i.p., daily for 7 days) to induce Tat-protein expression or received saline vehicle as a negative control (ie, remained uninduced). Following Dox- or vehicle-induction, mice were exposed to an additional cocaine-saline placeconditioning cycle and were then tested for place preference (see Figure 3a for schematic). As expected, an additional cycle of cocaine place-conditioning did not alter the established cocaine-CPP of saline-administered GT-tg control mice not expressing Tat protein (Figure $3 \mathrm{~b}$, striped left bar); however, exposure to Tat-protein resulted in a significant 3.1-fold potentiation of cocaine-CPP over the prior preference response after an additional cycle of cocaine place-conditioning $\left(\mathrm{F}_{(2,72)}=13.65, \quad p<0.05\right)$ (Figure 3b, striped gray bar).

\section{Presence of HIV-1 Tat Did Not Influence Rate of Extinction, But Reinstated Extinguished Cocaine-CPP}

The duration, extinction and reinstatement of cocaine-CPP were characterized in uninduced and Tat-induced GT-tg bigenic mice. Both uninduced and Tat-induced GT-tg mice were place-conditioned with four conditioning 'cycles' (see Figure $4 \mathrm{a}$ schematic, squares). Mice were tested for preference $24 \mathrm{~h}$ after the completion of conditioning

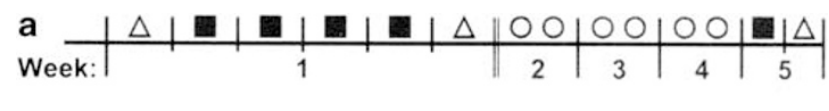

b

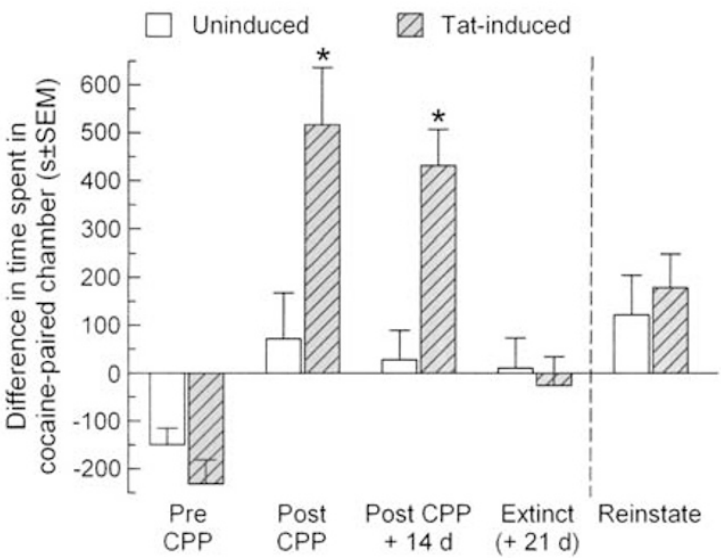

Figure 4 Human immunodeficiency virus I (HIV-I) Tat potentiated cocaine-conditioned place preference (CPP) does not influence the rate of extinction or the magnitude of reinstatement. (a) Time course schematic of extinction and reinstatement experiment. In the first week, mice were preference tested (triangles) the days preceding and following placeconditioning with cocaine $(10 \mathrm{mg} / \mathrm{kg}, \mathrm{s.c}$.) and saline daily for 4 days (squares). Mice were then tested for place preference twice weekly during weeks 2, 3, and 4 (circles). After extinction (3 weeks after conditioning; 5 weeks into the experiment), mice were given a priming conditioning cycle, and tested the following day again for place preference. (b) Results of extinction and reinstatement experiment. Uninduced (white bars) and Tatinduced (striped gray bars) mice demonstrated significant cocaine-CPP compared with pre-conditioning preferences. As expected, the Tatinduced mice showed a significantly potentiated response. This potentiation was still evident 2 weeks after conditioning. Three weeks after the completion of conditioning, induced and uninduced mice demonstrated extinction of CPP. Following a priming cycle of cocaine conditioning (dashed line), both sets of mice demonstrated reinstatement of a similar magnitude of place preferences (bars to right of dashed line). *Indicates significant difference from response of uninduced mice in same test session, $p<0.05$, repeated measures analysis of variance (ANOVA).

(Figure 4a, triangle) and twice weekly thereafter for 3 weeks (Figure $4 \mathrm{a}$, circles) until there was no longer a significant preference for the cocaine-paired chamber, a demonstration of extinction. After the preference for cocaine was no longer evident, mice were exposed to one additional conditioning cycle to induce reinstatement of cocaine-CPP (Carey et al, 2007). Preference was then examined in both uninduced and Tat-induced GT-tg bigenic mice to examine reinstatement of cocaine-CPP.

Repeated measures ANOVA indicated a significant interaction between test session and Dox condition $\left(\mathrm{F}_{(4,120)}\right.$ $=5.59, p<0.05) \quad$ (Figure $4 \mathrm{~b}$ ). Consistent with previous results, simple main effects indicated that Dox-induced GT-tg mice demonstrated a significant potentiation of cocaine-CPP compared with the post-conditioning preference of uninduced littermates $\left(\mathrm{F}_{(1,24)}=8.68, p<0.01\right)$ postCPP $(p<0.0001)$ and 2 weeks later $(p<0.001$; Figure $4 \mathrm{~b})$. However, after 3 weeks, both Tat-induced and uninduced mice demonstrated equivalent extinction of CPP, as preference for the cocaine-paired chamber did not statistically differ from pre-conditioning responses $(p>0.10$; Figure $4 \mathrm{~b}$ ). Notably, when exposed to an additional cycle of place-conditioning, both uninduced and Tat-induced mice demonstrated reinstatement of CPP $(p<0.01)$, but the 
reinstated preferences of the uninduced and Tat-induced mice did not differ significantly $(p=0.61$; Figure $4 \mathrm{~b}$, rightmost bars).

To test the hypothesis that exposure to Tat protein alone can reinstate an extinguished cocaine-CPP independent of cocaine-priming, C57BL/6J control mice and uninduced GT-tg bigenic mice were place-conditioned with cocaine and the response extinguished (see Figure 5a schematic). As expected, test session and Dox condition significantly interacted $\left(\mathrm{F}_{(5,275)}=5.23, p<0.05\right)$ (Figure $5 \mathrm{~b}$ ). Simple main effects indicated that both C57BL/6J control mice $\left(\mathrm{F}_{(5,155)}=\right.$ $8.27, p<0.05)$ and uninduced GT-tg mice $\left(\mathrm{F}_{(5,105)}=12.12\right.$, $p<0.05)$ demonstrated a significant preference for the cocaine-paired chamber upon the completion of placeconditioning $\left(p_{\mathrm{C} 57 \mathrm{BL} / 6 \mathrm{~J}}<0.0001 ; p_{\mathrm{GT}-\mathrm{tg}}<0.0001\right)$, and demonstrated extinction of the place-preference response 3 weeks later $\left(p_{\mathrm{C} 57 \mathrm{BL} / 6 \mathrm{~J}}=0.40 ; p_{\mathrm{GT}-\mathrm{tg}}=0.38\right.$; Figure $\left.5 \mathrm{~b}\right)$. Dox administration to $\mathrm{C} 57 \mathrm{BL} / 6 \mathrm{~J}$ control mice produced no change in the extinction response $(p=0.86)$, but significantly increased the time spent in the cocaine-paired chamber by GT-tg mice $(p<0.0001)$, suggesting that exposure to Tat-protein reinstated extinguished cocaine-CPP.

\section{DISCUSSION}

Substance abuse is highly comorbid with HIV infection (Mathers et al, 2008; Purohit et al, 2011), but relatively little is known regarding how HIV may impact the rewarding effects of abused drugs. These experiments utilized a bigenic mouse model capable of brain-specific expression of HIV-Tat protein to examine the hypothesis that exposure to Tat protein was sufficient to influence the psychostimulant and rewarding effects of cocaine. Once expressed, HIV-Tat prolonged the locomotor effects of cocaine and potentiated cocaine-CPP. Effects to enhance the rewarding properties of cocaine in a CPP paradigm occurred in a Doxdose- and duration-dependent manner. Tat expression did not influence the time to CPP-extinction or the magnitude of cocaine-induced reinstatement. However, induction of Tat following extinction produced a reinstatement of extinguished cocaine-CPP. These results demonstrate that central expression of HIV-Tat protein is sufficient to potentiate motivation for cocaine and extend previous findings of Tat-mediated dopaminergic activity and/or sensitization to cocaine's effects (Harrod et al, 2008; Ferris et al, 2010). Moreover, these data support the utility of the Tat bigenic mouse as an in vivo model to investigate the behavioral modifications caused by HIV-Tat in the context of an intact organism.

Tat modulation of dopaminergic activity within the CNS may contribute to its capacity to potentiate cocaine's psychomotor effects. Herein, we observed that Tat induction maintained cocaine-mediated hyperlocomotion for a longer duration than was observed when Tat was not induced, or when the transgene was not present (as is the case amongst control C57BL/6J mice). Consistent with these results, exogenous microinjection of a 72 -amino-acid Tat protein directly into the nucleus accumbens (NAc) of rats increased acute locomotor responding to cocaine (Harrod et al, 2008). These results are logical, given reports that Tat protein allosterically modulates DAT in a dose-dependent
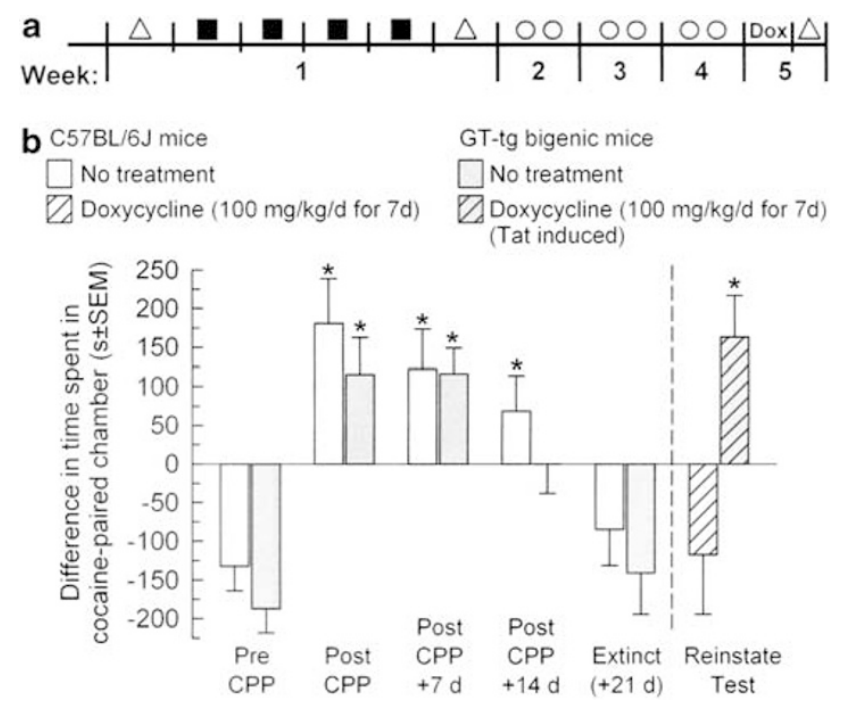

Figure 5 Expressing human immunodeficiency virus I (HIV-I) Tat protein reinstates extinguished cocaine-conditioned place preference (CPP). (a) Time course schematic of extinction and reinstatement experiment. In week I, C57BL/6J or uninduced GT-tg bigenic mice were preference tested (triangles) the days preceding and following placeconditioning with cocaine $(10 \mathrm{mg} / \mathrm{kg}, \mathrm{s.c}$.) and saline daily for 4 days (squares). Mice were tested for place preference twice weekly during weeks 2, 3, and 4 (circles). After extinction (3 weeks after conditioning; 5 weeks into the experiment) mice were induced to express Tat protein (doxycycline $100 \mathrm{mg} / \mathrm{kg}$, i.p., for 7 days) and tested again for place preference (right-most triangle). (b) Results of extinction and reinstatement experiment. C57BL/6J (white bars) and GT-tg bigenic (gray bars) mice demonstrated significant cocaine-CPP compared with pre-conditioning preferences. Three weeks after the completion of conditioning, mice demonstrate extinction of CPP. Following induction of HIV-I Tat protein, GT-tg bigenic, but not C57BL/6J controls, demonstrate a significant reinstatement of cocaine-CPP. *Indicates significant difference from respective pre-CPP response, $p<0.05$, repeated measures analysis of variance (ANOVA).

and reversible manner (Aksenov et al, 2001; 2006; Ferris et al, 2009; Zhu et al, 2009, 2011), inhibiting $\left[{ }^{3} \mathrm{H}\right] \mathrm{DA}$ uptake into striatal synaptosomes time- and concentration-dependently (Zhu et al, 2009). These actions may directly contribute to decreased DA recycling, subsequently increasing extracellular DA in the NAc to potentiate the psychostimulant effects of cocaine when both are present (Ferris et al, 2009, 2010). The NAc is an area integral to the addictive effects of psychostimulants (Kalivas and Volkow, 2005), and also a major reservoir in the brain for HIV (Wiley et al, 1998) likely to express Tat protein. As such, it seems likely that a dopaminergic mechanism is involved in Tat's potentiation of cocaine reward in the present behavioral study.

It should be noted that Tat potentiation of cocaine-CPP may arise from a number of direct and indirect detrimental effects on the CNS that serve to modulate dopaminergic tone. Tat produced neurotoxic effects in vivo when injected intracerebroventricularly in mice (Sabatier et al, 1991) and in vitro in cultured human and rat neurons (Nath et al, 1996; New et al, 1998; Maragos et al, 2002). Tat-induced oxidative stress has been associated with neurotoxicity and loss of function (Price et al, 2005), particularly in midbrain dopaminergic neurons (Aksenov et al, 2001; Aksenova et al, 2006). Elevated dopaminergic tone in mesolimbic 'reward 
circuits' that project through the ventromedial striatum is strongly linked to the reinforcing effects of drugs and drug addiction (Di Chiara et al, 2004; Kalivas and Volkow, 2005). As such, indirect changes to mesolimbic dopaminergic tone via neurotoxic effects of Tat in DA-rich brain regions may also exacerbate cocaine-psychostimulation. However, direct actions of Tat may be more likely to underlie these effects, as opposed to indirect effects of neurotoxic brain disorganization, given that potentiating effects were lost over time and were independent of longer-term differences in extinction and reinstatement.

In the present study, exposure to Tat protein in the absence of cocaine produced reinstatement of a previously extinguished CPP. These data suggest that exposure to Tat protein may increase the likelihood of relapse in abstinent subjects with a history of cocaine use. Although the mechanistic basis of this interaction is beyond the scope of this initial study, Tat protein modulates a number of intracellular pathways in vitro (Gibellini et al, 1998), which could feasibly contribute to this behavioral result, most notably extracellular-signal regulatory kinase mitogenactivated protein (ERK1/2 MAP) kinase (Rusnati et al, 2001). ERK1/2 MAP kinases have been implicated in both the reinforcing properties of cocaine (Valjent et al, 2000) and the reinstatement of cocaine self-administration ( $\mathrm{Lu}$ et al, 2005; Wells et al, 2013). The host of interactions between Tat and the brain highlight many avenues by which Tat may influence drug reward, and which will require additional research.

Together these data demonstrate the potential for actions of central HIV-Tat to increase the vulnerability to cocaine abuse. However, many individuals that acquire HIV do so from already established patterns of drug abuse (Nath et al, 2002; UNAIDS/WHO, 2005). It is therefore important to question how HIV-Tat may not only influence psychostimulant reward before drug exposure, but how it may influence craving in individuals demonstrating established drug abuse. Herein, we observed that induction of HIV-Tat potentiated the response to a subsequent additional cycle of cocaine place-conditioning in mice already demonstrating cocaine-CPP. Typically, one cycle of saline-cocaine place-conditioning is insufficient to produce or alter CPP; moreover, three cycles of conditioning does not produce a CPP significantly greater than that achieved with two cycles (McLaughlin et al, 2003; Brabant et al, 2005). As such, the present data support the notion that exposure to HIV-Tat protein may exert important effects over already established patterns of drug use. Although challenging to execute in mice, future investigations will aim to utilize self-administration (Ahmed and Kenny, 2011) to parse out the reinforcing effects of Tat on cocaine use.

In summary, the present data suggest that exposure to HIV-Tat protein is sufficient to potentiate the psychostimulant effects of cocaine. Importantly, these studies revealed extinction on a magnitude commensurate with non-Tat-induced controls, suggesting that some effects for drug reward may not be pervasive, and a therapeutic window for treatments targeting central Tat proteins (Mousseau et al, 2012) may prove efficacious. Given that psychostimulant users comprise a significant segment of the population of HIV-infected patients (UNAIDS/WHO, 2005;
Mathers et al, 2008), and HIV-infected drug users present with a more marked neurological progression of HIV dementia (UNAIDS/WHO, 2005; Purohit et al, 2011), studies examining the synergy between drug abuse and neurotoxic substances released during HIV infection such as Tat (Aksenov et al, 2001; 2006) may offer new insights into the behavioral changes correlated with the progression of HIV-1 Tat infection.

\section{FUNDING AND DISCLOSURE}

Dr McLaughlin has in the past received compensation for professional services from Pfizer and Phoenix Pharmaceuticals. The authors declare no conflict of interest.

\section{ACKNOWLEDGEMENTS}

This research was supported by an F31 (NS064872) to ANC, an R03 (DA16415) and an R01 (MH085607) to JPM, and funds from the State of Florida, Executive Office of the Governor's Office of Tourism, Trade, and Economic Development.

\section{AUTHORSHIP CONTRIBUTIONS}

JJP, ANC, JJH, and JPM participated in research design; JJP, ANC, CFS, and SMG acquired the data; JJH contributed new reagents; JJP, ANC, and JPM performed data analysis and contributed to the writing of manuscript.

\section{REFERENCES}

Ahmed SH, Kenny PJ (2011). Cracking the molecular code of cocaine addiction. ILAR J 52: 309-320.

Aksenov MY, Hasselrot U, Bansal AK, Wu G, Nath A, Anderson C et al (2001). Oxidative damage induced by the injection of HIV-1 Tat protein in the rat striatum. Neurosci Lett 305: 5-8.

Aksenov MY, Aksenova MV, Nath A, Ray PD, Mactutus CF, Booze RM (2006). Cocaine-mediated enhancement of Tat toxicity in rat hippocampal cell cultures: the role of oxidative stress and D1 receptor. Neurotoxicity 27: 217-228.

Aksenova MV, Silvers JM, Aksenov MY, Nath A, Ray PD, Mactutus CF et al (2006). HIV-1 Tat neurotoxicity in primary cultures of rat midbrain fetal neurons: changes in dopamine transporter binding and immunoreactivity. Neurosci Lett 395: 235-239.

Blanchard DC, Blanchard RJ (1999). Cocaine potentiates defensive behaviors related to fear and anxiety. Neurosci Biobehav Rev 23: 981-991.

Brabant C, Quertemont E, Tirelli E (2005). Influence of the dose and the number of drug-context pairings on the magnitude and the long-lasting retention of cocaine-induced conditioned place preference in C57BL/6J mice. Psychopharmacology 180: 33-40.

Berger JR, Arendt G (2000). HIV dementia: the role of the basal ganglia and dopaminergic systems. J Psychopharmacol 14: 214-221.

Carey AN, Borozny K, Aldrich JV, McLaughlin JP (2007). Reinstatement of cocaine place-conditioning prevented by the peptide kappa-opioid receptor antagonist arodyn. Eur J Pharmacol 569: 84-89.

Carey AN, Lyons AM, Shay CF, Dunton O, McLaughlin JP (2009). Endogenous kappa opioid activation mediates stress-induced deficits in learning and memory. J Neurosci 29: 4293-4300. 
Carey AN, Sypek EI, Singh HD, Kaufman MJ, McLaughlin JP (2012). Expression of HIV-Tat protein is associated with learning and memory deficits in the mouse. Behav Brain Res 229: 48-56.

Carey AN, Liu X, Mintzopoulos D, Paris JJ, Muschamp JW, McLaughlin JP et al (2013). Conditional Tat protein expression in the GT-tg bigenic mouse brain induces gray matter density reductions. Prog Neuropsychopharmacol Biol Psychiatry 43: 49-54.

Carr GD, Fibiger HC, Phillips AG (1989). Conditioned place preference as a measure of drug reward. In: Liebman JM, Cooper SJ (eds). The Neuropharmacological Basis of Reward. Oxford University Press: New York, pp 264-319.

Cass WA, Harned ME, Peters LE, Nath A, Maragos WF (2003). HIV-1 protein Tat potentiation of methamphetamine-induced decreases in evoked overflow of dopamine in the striatum of the rat. Brain Res 984: 133-142.

Di Chiara G, Bassareo V, Fenu S, De Luca MA, Spina L, Cadoni C et al (2004). Dopamine and drug addiction: the nucleus accumbens shell connection. Neuropharmacology 47: 227-241.

Ferris MJ, Fredrick-Duus D, Fadel J, Mactutus CF, Booze RM (2009). The human immunodeficiency virus-1-associated protein, Tat1-86, impairs dopamine transporters and interacts with cocaine to reduce nerve terminal function: a no-net-flux microdialysis study. Neuroscience 159: 1292-1299.

Ferris MJ, Frederick-Duus D, Fadel J, Mactutus CF, Booze RM (2010). Hyperdopaminergic tone in HIV-1 protein treated rats and cocaine sensitization. J Neurochem 115: 885-896.

Frankel AD, Young JA (1998). HIV-1: fifteen proteins and an RNA. Annu Rev Biochem 67: 1-25.

Gibellini D, Bassini A, Pierpaoli S, Bertolaso L, Milani D, Capitani S et al (1998). Extracellular HIV-1 Tat protein induces the rapid Ser133 phosphorylation and activation of CREB transcription factor in both Jurkat lymphoblastoid $\mathrm{T}$ cells and primary peripheral blood mononuclear cells. J Immunol 160: 3891-3898.

Gorman M (1998). An tale of two epidemics: HIV and stimulant use. Focus 13: 1-3.

Harrod SB, Mactutus CF, Fitting S, Hasselrot U, Booze RM (2008). Intra-accumbal Tat ${ }_{1-72}$ alters acute and sensitized responses to cocaine. Pharmacol Biochem Behav 90: 723-729.

Kalivas PW, Volkow ND (2005). The neural basis of addiction: a pathology of motivation and choice. Am J Psychiatry 162: 1403-1413.

Kim BO, Liu Y, Ruan Y, Xu ZC, Schantz L, He JJ (2003). Neuropathologies in transgenic mice expressing HIV-1 Tat protein under the regulation of the astrocyte-specific glial fibrillary acidic protein promoter and doxycycline. Am J Pathol 162: 1693-1707.

Lawson MA, Kelley KW, Dantzer R (2011). Intracerebroventricular administration of HIV-1 Tat induces brain cytokine and indoleamine 2,3-dioxygenase expression: a possible mechanism for AIDS comorbid depression. Brain Behav Immun 25: 1569-1575.

Lu L, Hope BT, Dempsey J, Liu SY, Bossert JM, Shaham Y (2005). Central amygdala ERK signaling pathway is critical to incubation of cocaine craving. Nat Neurosci 8: 212-219.

Malison RT, Best SE, van Dyck CH, McCance EF, Wallace EA, Laruelle $\mathrm{M}$ et al (1998). Elevated striatal dopamine transporters during acute cocaine abstinence as measured by [123I] beta-CIT SPECT. Am J Psychiatry 155: 832-834.

Maragos WF, Young KL, Turchan JT, Guseva M, Pauly JR, Nath A et al (2002). Human inmmunodeficiency virus-1 Tat protein and methamphetamine interact synergistically to impair striatal dopaminergic function. J Neurochem 83: 955-963.

Mathers BM, Dengenhardt L, Phillips B, Wiessing L, Hickman M, Strathdee SA et al (2008). Global epidemiology of injected drug use and HIV among people who inject drugs: a systemic review. Lancet 372: 1733-1745.
McLaughlin JP, Marton-Popovici M, Chavkin C (2003). $\mathrm{K}$ Opioid receptor antagonism and prodynorphin gene disruption block stress-induced behavioral responses. J Neurosci 23: $5674-5683$.

Mishra M, Vetrivel S, Siddappa NB, Ranga U, Seth P (2008). Cladespecific differences in neurotoxicity of human immunodeficiency virus-1 $\mathrm{B}$ and $\mathrm{C}$ Tat of human neurons: significance of dicysteine C30C31 motif. Ann Neurol 63: 366-376.

Mousseau G, Clementz MA, Bakeman WN, Nagarsheth N, Cameron M, Shi J et al (2012). An analog of the natural steroidal alkaloid cortistatin A potently suppresses Tat-dependent HIV transcription. Cell Host Microbe 12: 97-108.

Nath A (1999). Pathobiology of human immunodeficiency virus dementia. Sem Neurol 19: 113-127.

Nath A, Psooy K, Martin C, Knudsen B, Magnuson DS, Haughey N et al (1996). Identification of a human immunodeficiency virus type 1 Tat epitope that is neuroexcitatory and neurotoxic. J Virol 70: $1475-1480$.

Nath A, Hauser KF, Wojna V, Booze RM, Maragos W, Prendergast M et al (2002). Molecular basis for interactions of HIV and drugs of abuse. JAIDS 31: 62-69.

Navia BA, Cho ES, Petiio CK, Price RW (1986). The AIDS dementia complex: II neuropathology. Ann Neurol 19: 525-535.

New DR, Maggirwar SB, Epstein LG, Dewhurst S, Gelbard HA (1998). HIV-1 Tat induces neuronal death via tumor necrosis factor-alpha and activation of non-N-methyl-D-aspartate receptors by a NFkappaB-independent mechanism. J Biol Chem 273: $17852-17858$

Price TO, Ercal N, Nakaoke R, Banks WA (2005). HIV-1 viral proteins gp120 and Tat induce oxidative stress in brain endothelial cells. Brain Res 1045: 57-63.

Purohit V, Rapaka R, Shurtleff D (2011). Drugs of abuse, dopamine, and HIV-associated neurocognitive disorders/HIVassociated dementia. Mol Neurobiol 44: 102-110.

Rao VR, Sas AR, Eugenin EA, Siddappa NB, Bimonte-Nelson H, Berman JW et al (2008). HIV-1 clade-specific differences in the induction of neuropathogenesis. J Neurosci 28: 10010-10016.

Rusnati M, Urbinati C, Musulin B, Ribatti D, Albini A, Noonan D et al (2001). Activation of endothelial cell mitogen activated protein kinase $\operatorname{ERK}(1 / 2)$ by extracellular HIV-1 Tat protein. Endothelium 8: 65-74.

Sabatier JM, Vives E, Mabrouk K, Benjouad A, Rochat H, Duval A et al (1991). Evidence for neurotoxic activity of tat from human immunodeficiency virus type 1. J Virol 65: 961-967.

Sacktor N, Nakasujja N, Skolasky RL, Rezapour M, Robertson K, Musisi S et al (2009). HIV subtype D is associated with dementia, compared with subtype A, in immunosuppressed individuals at risk of cognitive impairment in Kampala, Uganda. Clin Infect Dis 49: $780-786$.

Staley JK, Hearn WL, Ruttenber AJ, Wetli CV, Mash DC (1994). High affinity cocaine recognition sites on the dopamine transporter are elevated in fatal cocaine overdose victims. J Pharmacol Exp Ther 271: 1678-1685.

UNAIDS/WHO (2005): UNAIDS/WHO AIDS epidemic update: December 2005.

Valjent E, Corvol JC, Pages C, Besson MJ, Maldonado R, Caboche J (2000). Involvement of the extracellular signal regulated kinase cascade for cocaine-rewarding properties. J Neurosci 20: 8701-8709.

Wallace DR, Dodson S, Nath A, Booze RM (2006). Estrogen attenuates gp120- and Tat 1-72-induced oxidative stress and prevents loss of dopamine transporter function. Synapse 59: 51-60.

Wei P, Garber ME, Fang SM, Fischer WH, Jones KA (1998). A novel CDK9-associated C-type cyclin interacts directly with HIV-1 Tat and mediates its high-affinity, loop-specific binding to TAR RNA. Cell 92: 451-462. 
Wells AM, Arguello AA, Xie X, Blanton MA, Lasseter HC, Reittinger AM et al (2013). Extracellular signal-regulated kinase in the basolateral amygdala, but not the nucleus accumbens core, is critical for context-response-cocaine memory reconsolidation in rats. Neuropsychopharmacology 38: 753-762.

Wiley CA, Soontornniyomkij V, Radhakrishnan L, Masliah E, Mellors J, Hermann SA et al (1998). Distribution of brain HIV load in AIDS. Brain Pathol 8: 277-284.

Wilson JM, Levey AI, Bergeron C, Kalasinsky K, Ang L, Peretti F et al (1996). Striatal dopamine, dopamine transporter, and vesicular monoamine transporter in chronic cocaine users. Ann Neurol 40: 428-439.
Yao H, Buch S (2012). Rodent models of HAND and drug abuse: exogenous administration of viral protein(s) and cocaine. J Neuroimmune Pharmacol 7: 341-351.

Zhu J, Ananthan S, Mactutus CF, Booze RM (2011). Recombinant human immunodeficiency virus-1 transactivator of transcription1-86 allosterically modulates dopamine transporter activity. Synapse 65: 1251-1254.

Zhu J, Mactutus CF, Wallace DR, Booze RM (2009). HIV-1 Tat protein-induced rapid and reversible decrease in $\left[{ }^{3} \mathrm{H}\right]$ dopamine uptake: dissociation of $\left[{ }^{3} \mathrm{H}\right]$ dopamine uptake and $\left[{ }^{3} \mathrm{H}\right]$ WIN 35,428 binding in rat striatal synaptosomes. J Pharmacol Exp Ther 329: 1071-1083. 